systematizing mind of the mathematician", he introduces vocabulary on the basis of groups of cognate words, explaining their derivations and connexions in an illuminating and memorable manner-if with occasional sidetracking into anecdotal material, or the considerations of historical and comparative phonology, which, although diverting and instructive, seem a little out of place in a brief course of this kind.

The lexical and grammatical material is presented in a clear and orderly manner, and, except for a few exotica in the early pronunciation exercises (the probability of kot-tomcat, žukbeetle, žoh-swindler, trup-corpse or yut-quarterdeck, occurring in mathematical papers seems extremely small!) the grammar is illustrated by examples such as "the problem reduces itself to such a choice of the function for which the integral has the least value" or "we shall explain some questions of the theory of generalized functions constructed by S. L. Sobolev and L. Schwartz". There are, unfortunately, a few slips, perhaps the most serious being the statement that the genitive of negation is an optional, not an obligatory, construction.

Again catering to the specific needs of his readership, who will, presumably, have their attention drawn to Russian mathematical papers by a notice in Mathematical Reviews, Dr Gould recommends the system of transliteration favoured by that journal (although it differs somewhat from both the international and standard American versions). Less happy is his suggestion that the student should "invent" names for those letters of the Cyrillic alphabet which have no English equivalent. It would surely have been far more beneficial to have taught the Russian names for letters-one can visualize a situation of considerable confusion, if, say, in an enquiry by telephone to a library, a follower of Dr Gould's suggested system attempted to spell out a title, saying "zee-check" for "zhe", or "eshch" for "shcha".

In general, however, this book tackles a difficult task straightforwardly and competently. Its selection of texts for continuous reading advances from elementary analytical geometry and calculus, through number theory, rings and fields, to Baire classifications, mathematical logic, Hilbert space and topology. Little provision, however, is made for the applied mathematician, save for one elementary text on the addition of vectors and a short passage on partial differential equations. In view of the vast literature on applied mathematics currently being produced in the Soviet Union, this is, perhaps, the most serious deficiency of the book. VERA RICH

\section{Dyslexic Disabilities}

Dyslexia and the Individual. (A Study of Reading Difficulty in "Word Blind" Children.) By Patrick Meredith. Pp. 190. (Elm Tree: London, November 1972.) £2.35.

IT would be easy to find fault with this book. There is no systematic marshalling of evidence, nor do any very firm conclusions emerge at the end. Clearly, however, Professor Meredith did not intend it to be that kind of book. What is being offered is not a systematic treatise on dyslexia but some personal reflexions.

Two main themes emerge. In the first place Professor Meredith delivers a blistering attack on traditional psychometrics (i.e., the alleged "measurement" of IQs, reading ages, and so on). He quotes with approval Eddington's dictum that "we can make nothing of measures without any note of the objects and circumstances to which they refer", and he points out that, when a child is being tested, the "circumstances to which (he) is responding ... usually include a great deal more than the particular test-items on which the psychologist is concentrating". His second theme is that we should try to become more sensitive to what happens when people are exposed to different spatial and temporal sequences. "Laterality", he tells us, "is full of surprises".

The attack on psychometrics seems to me undoubtedly correct. I also agree that dyslexic children often fail "to co-ordinate, in time, their perceptions of space". There is still much in the book, however, which I find obscure, and there is even a certain amount which I suspect to be nonsense; for example, "The space-time of the child is a field of events, curled up and carved up in the convolutions of his cortex". On page 77 he promises a further book devoted to "orthochorics", which he refers to as a kind of "behavioural geometry". From the present book the case for such a science is by no means made out, but here one must suspend judgment until more details are published.

I have two further comments. First, it seems to me misleading that the book has been given the sub-title, "A Study of Reading Difficulty" (my italics). Professor Meredith would, I am sure, be the first to agree that for many children with the dyslexic cluster of disabilities reading is the least of their problems; and I think it should be stressed that, in spite of the incorrect associations with the Latin word lego, dyslexia is not just a difficulty with reading. Secondly, I am surprised that Professor Meredith shows so little enthusiasm for the work of Skinner. The "cumulative record", used by
Skinner and his followers to provide a spatial representation of an organism's behaviour over time, is just the kind of notation which he might have been expected to favour, while Skinner's concept of the "discriminative stimulus" is one which forces experimenters to take serious note of the particular "circumstances" in which an organism's responses occur. Professor Meredith's views seem to me to have more in common with those of Skinner than perhaps he realizes.

T. R. MiLes

\section{Radiation Protection}

An Introduction to Radiation Protection. By Alan Martin and Samuel A. Harbison. Pp. $\mathrm{xi}+216+4$ plates. (Chapman and Hall: London, October 1972.) £1.95.

THIS book is intended to introduce those who have a science education to "O" level or equivalent standard to the principles and practice of radiological protection. Those persons most likely to find the book of value are trainee technicians and health physics monitors who will become responsible for the day-to-day control of radiation hazards in nuclear power stations, research establishments, hospitals and industrial premises where employees are exposed, or potentially exposed, to ionizing radiation.

The book contains seventeen chapters and at the end of each there is a summary and a number of revision questions which could be useful for both student and teacher at the level of City and Guilds examinations. The first few chapters deal with elementary theory of the structure of matter, radioactivity and radiation units. The middle chapters are on protection standards and methods of monitoring. The later chapters introduce practical aspects such as waste disposal, legislation, transport regulations and radiation emergencies, and these will be of particular interest as this material is not readily available in such an easily readable form.

Two chapters are of lower quality than the rest, one on "Biological Effects of Radiation" and the other on "The Internal Radiation Hazard". The authors could improve the former by the use of more up-to-date material from the excellent summary of the subject published as Radiobiological Factors in Manned Space Flight. ${ }^{1}$ The latter is too short for such a complex topic. Its readability could be improved by a more liberal use of diagrams to illustrate metabolic pathways for ingestion and inhalation. This chapter also contains some errors of fact. In one 